\title{
Powdered activated carbon (PAC) - vacuum-assisted air gap membrane distillation (V-AGMD) hybrid system to treat wastewater containing surfactants: Effect of operating conditions
}

\author{
Yusik Kim, Yongjun Choi, Jihyeok Choi, Sangho Lee ${ }^{\dagger}$ \\ School of Civil and Environmental Engineering, Kookmin University, Jeongneung-Dong, Seongbuk-Gu, Seoul, 136-702, Republic of Korea
}

\begin{abstract}
Membrane distillation (MD), which uses hydrophobic porous membranes with a temperature gradient to produce pure water, has the potential to treat high-salinity wastewater. However, it cannot directly treat wastewater containing surfactants, which lower the surface tension and thus result in membrane wetting. To overcome this limitation, this study proposed a hybrid process consisting of powdered activated carbon (PAC) adsorption and $\mathrm{MD}$, where PAC removes the surfactants in the wastewater to alleviate the wetting of the MD membranes. A bench-scale vacuum-assisted air gap MD (V-AGMD) equipment was adopted for the treatment of synthetic wastewater containing inorganic salts and surfactants. The conductivity of the permeate from V-AGMD was continuously monitored to detect membrane wetting. Without the use of PAC, the MD membrane was wetted within a short period, which decreased as the surfactant concentration increased. On the other hand, the addition of PAC retards the onset of wetting even at higher surfactant concentrations. The effectiveness of the PAC addition to the MD system on wetting control was examined under various conditions to elucidate its mechanism.
\end{abstract}

Keywords: High-salinity wastewater, Membrane distillation (MD), Surfactant, Vacuum-assisted AGMD (V-AGMD), Wetting

\section{Introduction}

Demand for freshwater is rapidly increasing worldwide due to population growth, industrialization, and urbanization while the amount of available freshwater is limited. [1-3]. To resolve the imbalance between the water resource and demand, water reclamation has drawn attention as a sustainable way of providing additional water supply. Water reclamation is the processing of wastewater to meet the water quality requirement for its reuse [4]. Membrane technology such as reverse osmosis (RO) is a key technique for water reclamation due to its high removal efficiency of target contaminants [5]. However, the operation of RO is restricted by the barriers including the osmotic pressure, concentration polarization, and membrane fouling [6]. This is especially problematic when industrial wastewater containing high concentrations of ionic species should be reclaimed as the process water.

Such limitations of RO has motivated the development of novel technologies that allow the treatment or reuse of high salinity wastewater. Being one of them, membrane distillation (MD) holds the potential to allow the production of high-purity water [7]. MD is one of the membrane contactors and can separated vapors from liquid-phase water using hydrophobic porous membranes [8-11]. There are four typical MD configurations, including direct contact $\mathrm{MD}$ (DCMD), air gap MD (AGMD), sweeping gas MD (SGMD), and vacuum MD (VMD) [12-14]. Among them, AGMD is a preferred configuration for practical implementation due to its high thermal efficiency and the capability of stable operation [13]. Nevertheless, AGMD has drawbacks associated with relatively low flux and productivity compared with DCMD or VMD [12, 15, 16]. Accordingly, a handful of works have been done to overcome this shortcoming by increasing the flux of AGMD with the application of vacuum pressure [12, 17, 18].

While AGMD is applicable for the reclamation of high-salinity wastewater, it may suffer from critical problems caused by membrane wetting [19, 20]. Membrane wetting is regarded as a primary barrier to the widespread industrial use of $\mathrm{MD}$ technology. Membrane wetting involves three stages: surface wetting, partial

Received July 02, 2020 Accepted September 25, 2020

${ }^{\dagger}$ Corresponding author

Email: sanghlee@kookmin.ac.kr

Tel: +82-2-910-4529 Fax: +82-2-910-4939 mits unrestricted non-commercial use, distribution, and
medium, provided the original work is properly cited.

Copyright (C) 2021 Korean Society of Environmental Engineers 
wetting, and fully wetting [19, 20]. Surface wetting means that only the membrane surface is wetted by the liquid and does not affect membrane performance. Partial wetting can lead to a reduction in salt rejection as the membrane pores are partially filled with liquid. When the membrane pores are fully filled with liquid, the membrane becomes fully wet. A fully wetted membrane will lose its separation through MD [19].

Membrane wetting may occur when feed water contains surfactants that can reduce surface tension [21, 22]. Surfactants are widely used in household goods, detergents, industrial processes, and pesticides [23]. Surfactants are usually amplified organic compounds, meaning they contain both hydrophobic and hydrophilic groups. This structure of the surfactant causes the hydrophobic tail to adhere to the membrane surface and pore, resulting in hydrophilization of the membrane. Therefore, special attention must be paid to wastewater containing surfactants in the MD process. Various techniques, such as physical, chemical, biological, and membrane treatment, have been used to remove surfactants as a part of wastewater treatment [24]. To the best of the authors knowledge, however, few works have attempted to remove surfactants from the feed water to mitigate the wetting of $\mathrm{MD}$ membranes.

In this paper, a technique based on activated carbon (AC) adsorption was proposed to mitigate the wetting of $\mathrm{MD}$ membranes during the treatment of high-salinity feed water containing surfactants. A bench-scale vacuum-assisted AGMD (V-AGMD) system was operated without and with added powdered activated carbon (PAC) and the wetting properties were compared. Experiments were conducted to analyze the effect of operating conditions and to elucidate the different observed wetting behaviors. The novelty of this work lies on the combination of PAC adsorption and V-AGMD for the treatment of high-salinity and low surface tension wastewater. Although many studies have been done in the integration of PAC with pressure-driven membranes [25-28], there have been few works on the application of PAC in the V-AGMD process especially for wetting control.

\section{Materials and Methods}

\subsection{Materials}

The hydrophobic polyvinylidene fluoride (PVDF) membranes were purchased from Merck Millipore (GVHP, Merck Millipore, U.S.A.). The average pore size, thickness, and porosity of the membranes are $0.22 \mu \mathrm{m}, 125 \mu \mathrm{m}, 75 \%$, respectively. The PAC was obtained from Samchun Pure Chemical Co. Ltd. Korea. Sodium dodecyl sulfate (SDS) and $\mathrm{NaCl}$ were purchased from Sigma Aldrich and they were used to prepare the synthetic wastewater for $\mathrm{MD}$ experiments.

\subsection{Batch adsorption Experiments}

Batch adsorption was carried out in a $1,000 \mathrm{~mL}$ flask to investigate the adsorption of SDS by the PAC. SDS solutions with the initial concentrations ranging from $1.71 \mathrm{mg} / \mathrm{L}$ to $80 \mathrm{mg} / \mathrm{L}$ were prepared. The temperature of the solution was set to $60^{\circ} \mathrm{C}$ and the PAC dose was $0.6 \mathrm{~g}$. It took about $1 \mathrm{~h}$ to reach adsorption equilibrium in this experiment. After equilibrium, the PAC was separated from the solution by filtration using $0.45 \mathrm{~m}$ Whatman filter papers. Then the concentrations of SDS were measured using a spectrophotometer (DR4000, Hach). The adsorption capacity was determined based on the difference between the initial and final SDS concentrations.

\subsection{V-AGMD}

A schematic diagram of the experimental setup for V-AGMD is shown in Fig. 1. The membrane cell was made of acrylic resin and its depth, width, and length were $2 \mathrm{~mm}, 20 \mathrm{~mm}$, and $60 \mathrm{~mm}$, respectively. The effective membrane area was $0.0012 \mathrm{~m}^{2}$. The temperature of the feed and coolant was maintained at $60^{\circ} \mathrm{C}$ and $20^{\circ} \mathrm{C}$, respectively. The flow rates were set to $0.6 \mathrm{~L} / \mathrm{min}$ for the feed and $0.4 \mathrm{~L} / \mathrm{min}$ for the coolant. Deionized (DI) water was used as the feed solution to measure the pure water flux as a function of vacuum pressure.

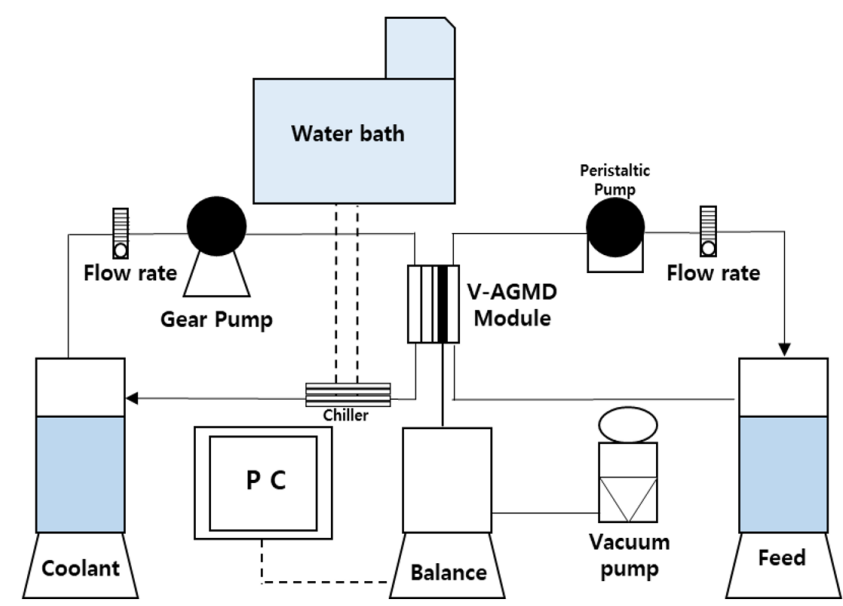

Fig. 1. Schematic diagram of laboratory-scale V-AGMD system.

\subsection{Effect of SDS on Membrane Wetting}

The high-salinity synthetic wastewater of varied SDS concentration was prepared to investigate the effect of SDS on membrane wetting in the V-AGMD process. The compositions of the synthetic wastewater are presented in Table 1. The V-AGMD experiments were carried out with the vacuum pressure of 0.5 bar. The temperatures and flow rates were the same as those of the pure water tests. In the V-AGMD system, the flux increases due to the pressure difference between the feed and permeate if wetting occurred. The permeate conductivity also increases with the progress of wetting because the feed water penetrates the wetted pores and mixed with the permeate. Accordingly, both flux and permeate conductivity were continuously monitored to examine the progress of fouling and wetting.

\subsection{Control of Membrane Wetting by PAC Adsorption}

To mitigate the wetting by SDS in the synthetic wastewater, the adsorption by PAC was applied to the V-AGMD system. Two different methods of PAC adsorption were compared. In the first method, the PAC was directed added to the feed tank of the V-AGMD system to let the adsorption occur during the $\mathrm{MD}$ operation. In the second method, the PAC was mixed with the feed water for 1 hour and 
Table 1. Summary of Experimental Conditions

\begin{tabular}{|c|c|c|c|}
\hline Configuration & PAC & Feed solution & $\begin{array}{l}\text { Vacuum } \\
\text { pressure }\end{array}$ \\
\hline \multirow{3}{*}{ V-AGMD } & - & $\begin{array}{l}\mathrm{NaCl} 50,000 \mathrm{mg} / \mathrm{L} \\
\text { SDS } 3 \mathrm{mg} / \mathrm{L}\end{array}$ & $0.5 \mathrm{bar}$ \\
\hline & - & $\begin{array}{l}\mathrm{NaCl} 50,000 \mathrm{mg} / \mathrm{L} \\
\quad \mathrm{SDS} 5 \mathrm{mg} / \mathrm{L}\end{array}$ & $0.5 \mathrm{bar}$ \\
\hline & - & $\begin{array}{l}\mathrm{NaCl} 50,000 \mathrm{mg} / \mathrm{L} \\
\mathrm{SDS} 7 \mathrm{mg} / \mathrm{L}\end{array}$ & $0.5 \mathrm{bar}$ \\
\hline \multirow{4}{*}{$\begin{array}{l}\text { V-AGMD } \\
\text { with PAC } \\
\text { adsorption }\end{array}$} & $\begin{array}{c}0.6 \mathrm{~g} \\
\text { (No prefiltration) }\end{array}$ & $\begin{array}{l}\mathrm{NaCl} 50,000 \mathrm{mg} / \mathrm{L} \\
\text { SDS } 3 \mathrm{mg} / \mathrm{L}\end{array}$ & 0.5 bar \\
\hline & $\begin{array}{c}0.6 \mathrm{~g} \\
\text { (No prefiltration) }\end{array}$ & $\begin{array}{l}\mathrm{NaCl} 50,000 \mathrm{mg} / \mathrm{L} \\
\quad \mathrm{SDS} 3 \mathrm{mg} / \mathrm{L}\end{array}$ & $0.65 \mathrm{bar}$ \\
\hline & $\begin{array}{c}0.6 \mathrm{~g} \\
\text { (No prefiltration) }\end{array}$ & $\begin{array}{l}\mathrm{NaCl} 50,000 \mathrm{mg} / \mathrm{L} \\
\quad \mathrm{SDS} 3 \mathrm{mg} / \mathrm{L}\end{array}$ & $0.8 \mathrm{bar}$ \\
\hline & $\begin{array}{c}0.6 \mathrm{~g} \\
\text { (Prefiltration) }\end{array}$ & $\begin{array}{l}\mathrm{NaCl} 50,000 \mathrm{mg} / \mathrm{L} \\
\text { SDS } 3 \mathrm{mg} / \mathrm{L}\end{array}$ & $0.8 \mathrm{bar}$ \\
\hline
\end{tabular}

then removed by the filter paper before the MD operation. In both cases, the initial SDS concentration was fixed at $3 \mathrm{mg} / \mathrm{L}$ and the vacuum pressure was adjusted from 0.5 bar to 0.8 bar, as shown in Table 1.

The permeate flux was presented in terms of time and volume concentration factor (VCF). The VCF, defined as a ratio of the feed volume to concentrate volume, indicates the extent of concentration:

$$
V C F=\frac{V_{f}}{V_{c}}=1+\frac{V_{p}}{V_{c}}
$$

where $V_{f}, V_{c}$, and $V_{\mathrm{p}}$ are defined as the volume of feed, concentrate, and permeate, respectively. The solute concentrations of the permeate were measured at different concentration factors.

\subsection{Contact angle Measurement}

The liquid contact angle (CA) was measured after the V-AGMD experiments. The CA of the membranes was measured by the sessile drop contact angle technique using a CA measurement device (Smart Drop, South Korea). First, membrane samples were placed on a plate and then water droplets $(3 \sim 4 \mathrm{~mL})$ were dropped onto the membrane surface. In a stationary state, the camera in the device captured an image of the droplet and the CA was automatically determined by the software. At least seven measurements were made for each sample and the average CA value was recorded.

\subsection{Liquid entry Pressure Measurement}

The liquid entry pressures (LEPs) were also measured after the V-AGMD experiments. LEP is the minimum pressure required to enable water to penetrate a membrane's pores. LEP is affected by the hydrophobicity of the membrane, the maximum pore size, and the shape of the pores [29]. For the current study, the LEP of the membranes was measured using an in-house LEP apparatus. First, $50 \mathrm{~mL}$ DI water was added to the water chamber, then a dry membrane sample (with an effective surface area of $7 \mathrm{~cm}^{2}$ ) was placed on the apparatus. Then nitrogen gas was supplied to the bottom of the water chamber. The pressure of the nitrogen gas was increased in a stepwise manner until the first droplet of water was observed on the membrane surface. To confirm reproducibility, at least three measurements were taken.

\subsection{Scanning Electron Microscopy}

The samples were coated with Pt. The surfaces and cross-sections of the membranes were then examined by FE-SEM (FE-SEM 7800F Prime, JEOL Ltd. Japan).

\section{Result and Discussion}

\subsection{Effect of SDS Concentration on Membrane Wetting}

Since wetting is related to the reduction of the surface tension of the feed solution, the addition of SDS is expected to accelerate it [30]. Moreover, SDS may also adsorb on the membrane surface, reduce its surface tension, and thus result in wetting. To examine how SDS affects the wetting, a series of $\mathrm{MD}$ experiments were carried using feed solutions with different SDS concentrations. In Fig. 2(a), where there was no SDS added to the feed solution, the flux and permeate conductivity were stable up to the operation time of 4,500 $\mathrm{min}$. After 5,000 $\mathrm{min}$, the permeate conductivity began to increase, indicating that wetting started. Without SDS, wetting occurred due to membrane fouling due to salt precipitation [19]. Nevertheless, it was observed only after a long period. The flux and permeate conductivity with the addition of $3 \mathrm{mg} / \mathrm{L}$ SDS are shown in Fig. 2(b). The flux increased from the beginning and the conductivity increased after $200 \mathrm{~min}$, suggesting that wetting happened from the early stage of the $\mathrm{MD}$ operation.

The extent of wetting became more significant when SDS concentration increased. As shown in Fig. 2(c), the flux increased from the beginning at the SDS concentration of $5 \mathrm{mg} / \mathrm{L}$. Moreover, the conductivity increased up to $1,376 \mathrm{~S} / \mathrm{cm}$ within $600 \mathrm{~min}$. A further increase in the SDS concentration to $7 \mathrm{mg} / \mathrm{L}$ resulted in a higher increasing rate of the flux and conductivity as depicted in Fig. 2(d). To quantitatively compare the effect of SDS concentrations on wetting, $\mathrm{NaCl}$ rejection was calculated at $600 \mathrm{~min}$ in each case. Without SDS, the $\mathrm{NaCl}$ rejection by $\mathrm{MD}$ was $99.98 \%$. However, the $\mathrm{NaCl}$ rejections at SDS concentrations of 3, 5, and, $7 \mathrm{mg} / \mathrm{L}$ were 98.94, 98.24, and $96.12 \%$, respectively. Compared with the case without SDS, the salt passage increased by 45.4, 75.9, and 167 times, respectively, at the SDS concentrations of 3,5 , and $7 \mathrm{mg} / \mathrm{L}$.

After the MD experiment, the liquid entry pressure (LEP) and the contact angle of the membranes were measured. The intact membrane had the LEP of 1.910 .22 bar and the contact angle of $126.781 .0^{\circ}$. After the MD experiments, the LEP and contact angle were reduced to zero in all cases. These results confirmed that wetting occurred during the $\mathrm{MD}$ operation.

\subsection{Adsorption of SDS by PAC}

It is evident from Fig. 2 that a more severe wetting was induced with an increased SDS concentration. This suggests that the wetting may be mitigated by reducing the SDS concentration. 

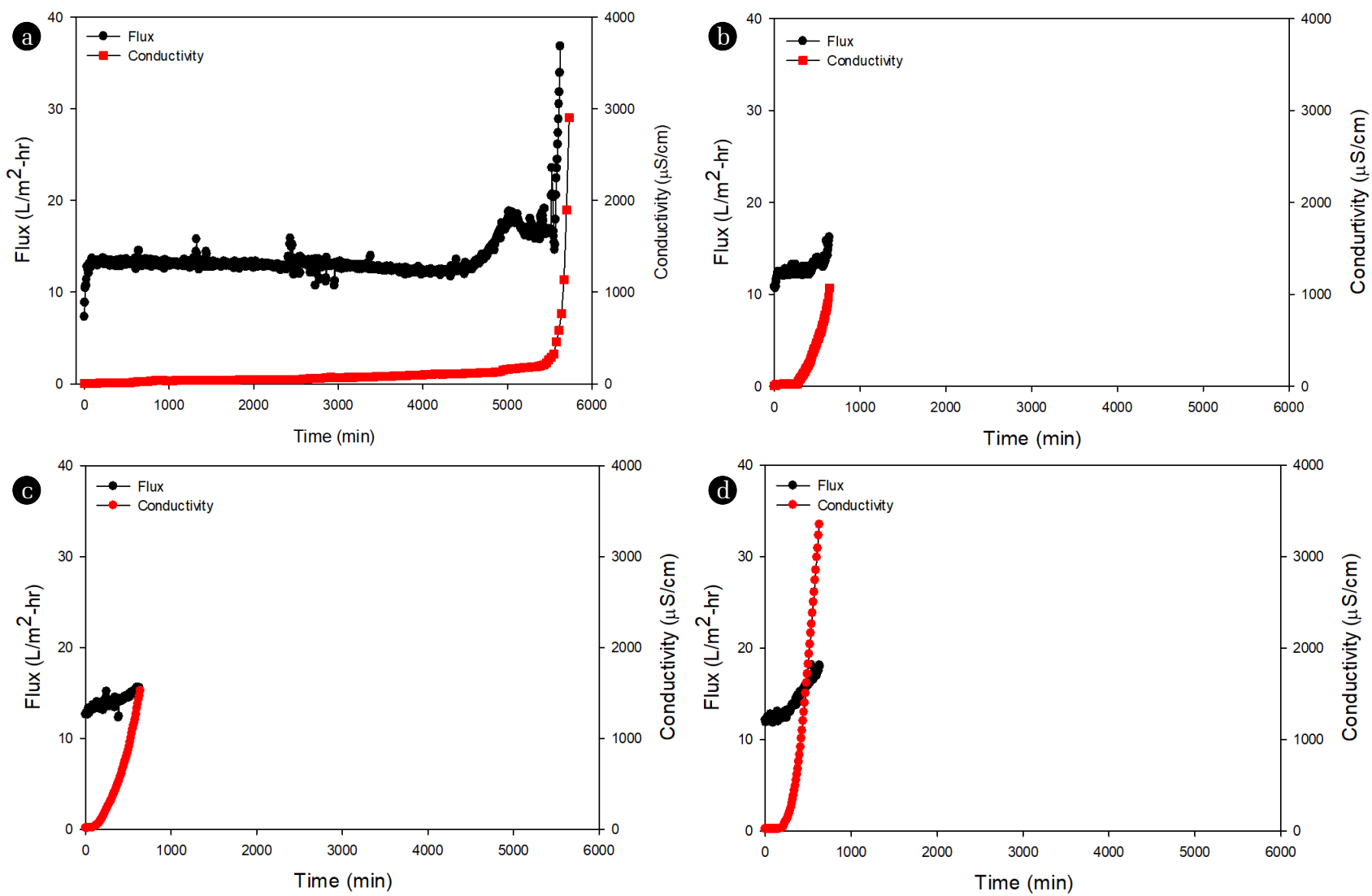

Fig. 2. Effect of SDS concentration in the synthetic feed water on flux and permeate conductivity in V-AGMD process. (Conditions: feed temperature; $60^{\circ} \mathrm{C}$; coolant temperature; $20^{\circ} \mathrm{C}$, feed flow rate; $600 \mathrm{~mL} / \mathrm{min}$; vacuum pressure, 0.5 bar; feed solution: $\mathrm{NaCl} 50,000 \mathrm{mg} / \mathrm{L}$ and SDS 0 7 mg/L) (a) SDS $0 \mathrm{mg} / \mathrm{L}$ (b) SDS $3 \mathrm{mg} / \mathrm{L}$ (c) SDS $5 \mathrm{mg} / \mathrm{L}$ (d) SDS $7 \mathrm{mg} / \mathrm{L}$.

Accordingly, PAC was considered to reduce SDS concentration by adsorption. First, the adsorption properties of SDS onto PAC was analyzed in batch experiments. Two isotherm models, including Langmuir and Freundlich isotherms, were fitted to the experimental data for the analysis of the mechanism of SDS adsorption by the PAC [31]:

Langmuir equation:

$$
\frac{c_{e}}{q_{e}}=\frac{1}{q_{m} K_{L}}+\frac{c_{e}}{q_{m}}
$$

Freundlich equation:

$$
\log q_{e}=\log K_{F}+\frac{1}{n} \log c_{e}
$$

where $\mathrm{C}_{\mathrm{e}}$ is the equilibrium concentration of the adsorbate (SDS) on the adsorbent (PAC), $q_{e}$ is the amount of the adsorbate at equilibrium, $K_{L}$ is the Langmuir constant related to the free adsorption energy and the reciprocal of the concentration at which half-saturation of the adsorbent is reached, $q_{m}$ is the monolayer adsorption capacity, and $K_{F}$ and 1/n are the Freundlich constants, which correspond to adsorption capacity and adsorption intensity, respectively.

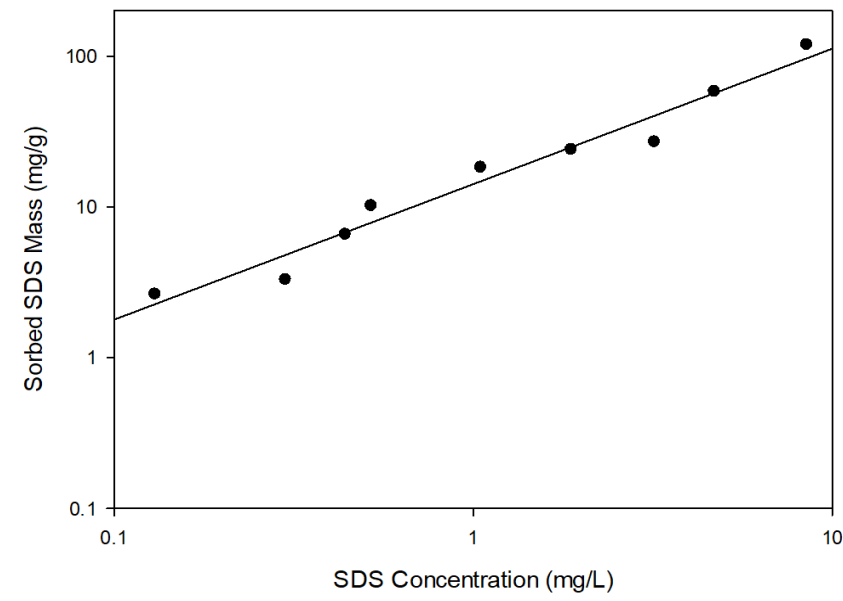

Fig. 3. Adsorption isotherm of SDS by PAC.

The parameters determined by the Langmuir equation and Freundlich equation were listed in Table 2. The Freundlich model fit shows a higher $\mathrm{R}^{2}$ than the Langmiur model. The Freundlich isotherm of SDS adsorption was plotted in Fig. 3. The $K_{F}$ and $1 / n$ for the Freundlich model were $1.1514 \mathrm{mg} / \mathrm{g}$ and 0.8988 , respectively. 
Table 2. Comparison of Adsorption Isotherm Model Fits

\begin{tabular}{lcc}
\hline Adsorption model & Estimated model parameters & $\mathbf{R}^{2}$ \\
\hline Langmuir & $\mathrm{KL}=1.407 \mathrm{~L} / \mathrm{mg}$ & 0.8944 \\
$\mathrm{qm}=13.42 \mathrm{mg} / \mathrm{g}$ & \\
\hline Freundlich & $\mathrm{KF}=1.1514 \mathrm{mg} / \mathrm{g}$ & 0.9629 \\
& $1 / \mathrm{n}=0.8988$ & \\
\hline
\end{tabular}

\subsection{Control of Wetting by PAC Adsorption}

\subsubsection{Effect of PAC addition}

After the batch adsorption tests, $\mathrm{MD}$ experiments were carried out to investigate the effect of PAC on membrane wetting by SDS. The feed solution containing 50,000 mg/L NaCl and $3 \mathrm{mg} / \mathrm{L}$ SDS was prepared for the $\mathrm{MD}$ experiment. PAC was directly added to the feed tank and recirculated during the MD operation. The results are presented in Fig. 4. Compared with Fig. 2(b), which is the results of the $\mathrm{MD}$ experiment using the same feed solution without PAC addition, the flux and permeate conductivity were maintained almost constant for a longer period of operation time. In Fig. 2(b), the flux and conductivity increased from the beginning but they were stable up to 5,700 min in Fig. 4. Since these results are similar to those without SDS (Fig. 2(a)), likely, the increases in flux and conductivity in Fig. 4 are also attributed to the fouling due to $\mathrm{NaCl}$ precipitation.

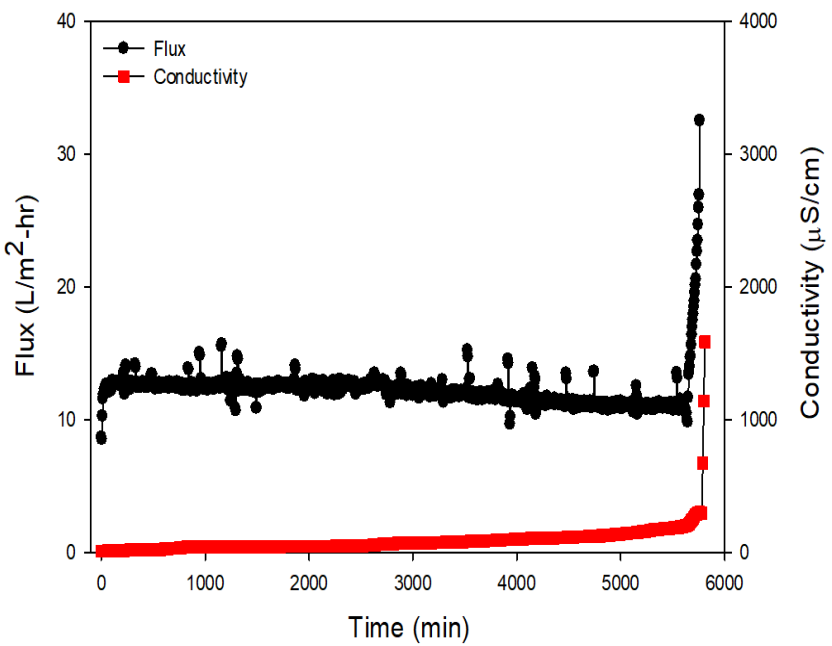

Fig. 4. Effect of PAC addition on flux and permeate conductivity in V-AGMD process. (Conditions: feed temperature; $60^{\circ} \mathrm{C}$; coolant temperature; $20^{\circ} \mathrm{C}$, feed flow rate; $600 \mathrm{~mL} / \mathrm{min}$; vacuum pressure, 0.5 bar; feed solution: $\mathrm{NaCl} 50,000 \mathrm{mg} / \mathrm{L}$ and SDS $3 \mathrm{mg} / \mathrm{L}$ ).

\subsubsection{Effect of vacuum pressure on wetting mitigation by PAC adsorption}

In V-AGMD, the application of vacuum improves the flux and productivity. As shown in Fig. 5, the pure water flux in V-AGMD increase from $5.5 \mathrm{~L} / \mathrm{m}^{2}-\mathrm{h}$ to $28 \mathrm{~L} / \mathrm{m}^{2}-\mathrm{h}$ with vacuum pressure. However, an increase in the vacuum pressure increases the risk of wetting because of the hydraulic pressure difference across the membrane. This is because only the vacuum pressure of $0.5 \mathrm{bar}$ was considered in Fig. 2. However, it was expected that a higher

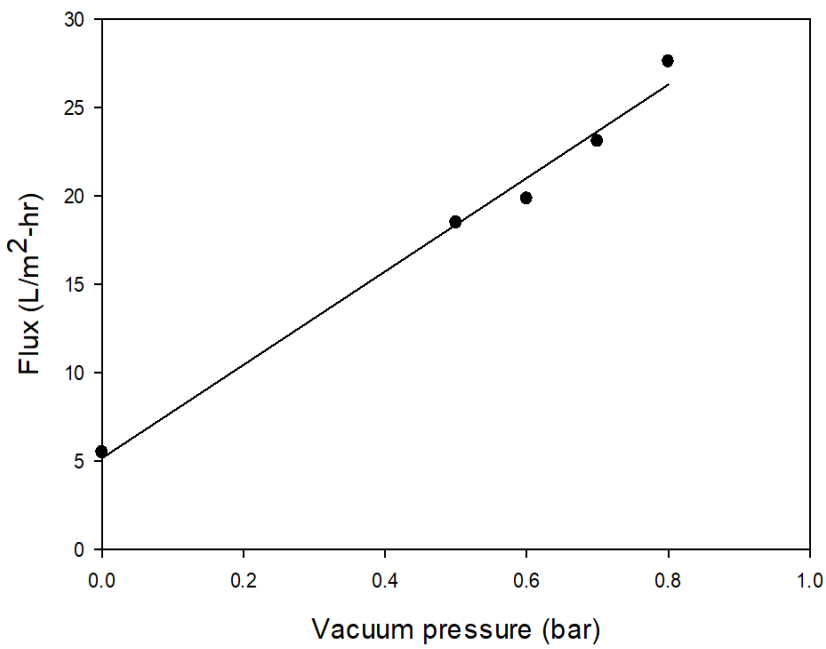

Fig. 5. Correlation with vacuum pressure and pure water flux in V-AGMD process. (Conditions: feed temperature; $60^{\circ} \mathrm{C}$; coolant temperature; $20^{\circ} \mathrm{C}$, feed flow rate; $600 \mathrm{~mL} / \mathrm{min}$; vacuum pressure, 0 $\sim 0.8$ bar; feed solution: deionized water).

vacuum pressure could be applied in V-AGMD with PAC because of a reduced risk of the wetting due to PAC adsorption.

Fig. 6(a) shows the changes in flux and permeate conductivity in V-AGMD at 0.65 bar vacuum. The initial flux was maintained at $18 \mathrm{~L} / \mathrm{m}^{2}$-h until 3,500 min and then abruptly increased. The permeate conductivity also increased after 3,600 min. When the vacuum pressure was 0.5 bar (Fig. 4), the flux and conductivity were almost constant before 5,700 min. Compared with these results, the wetting occurred more rapidly at higher vacuum pressure. Nevertheless, the addition of PAC is effective to mitigate the wetting by SDS. Since the wetting occurred after $200 \mathrm{~min}$ at 0.5 bar without PAC (Fig. 2(b)), more severe wetting should occur at 0.65 bar without PAC. In Fig. 6(b), the vacuum pressure was set to 0.8 bar in V-AGMD with PAC. The flux was initially $22 \mathrm{~L} / \mathrm{m}^{2}-\mathrm{h}$ and increased after 2,700 min. At the similar time, the permeate conductivity increased, indicating the occurrence of wetting. Again, the addition of PAC was found to be effective to mitigate the wetting by SDS but the effect became lower at the higher vacuum pressure.

When the initial flux is different, it is sometimes misleading to analyze the changes in fouling and wetting in terms of operation time. This is because the feed concentration in $\mathrm{MD}$ systems may be different even at the same operation time in such cases. Accordingly, the results in Fig. 4, Fig. 6(a), and Fig. 6(b) were further analyzed in terms of VCF. As shown in Fig. S1(a) in the supplementary material, the flux increased due to the wetting at VCF of 3.3, 2.5, and 1.8, respectively, when the vacuum pressures were $0.5,0.65$, and 0.8 bar. The permeate conductivity also increased at 3.2, 2.5, and 2.4, respectively, as depicted in Fig. S1(b). Based on these results, it can be concluded that both the time and VCF for the wetting occurrence decrease by increasing the vacuum pressure. In V-AGMD, the wetting occurs when the applied vacuum is higher than the liquid entry pressure. Accordingly, an increase in the vacuum pressure should accelerate the wetting if all the other conditions are the same. 

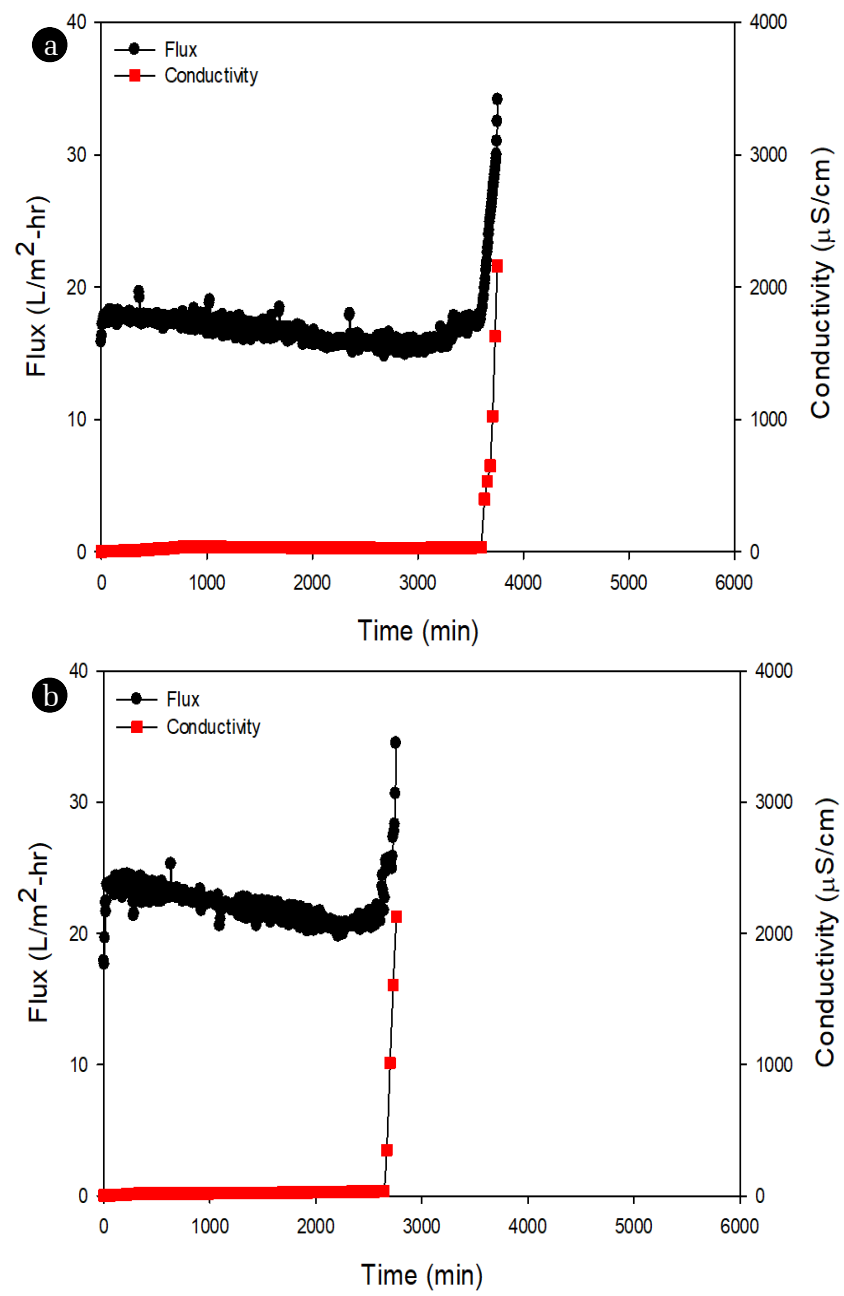

Fig. 6. Dependence of flux and permeate conductivity on time in V-AGMD process with PAC adsorption under different vacuum pressures. (Conditions: feed temperature; $60^{\circ} \mathrm{C}$; coolant temperature; 20 ${ }^{\circ} \mathrm{C}$, feed flow rate; $600 \mathrm{~mL} / \mathrm{min}$; feed solution: $\mathrm{NaCl} 50,000$ $\mathrm{mg} / \mathrm{L}$ and SDS $3 \mathrm{mg} / \mathrm{L}$; PAC dose, $0.6 \mathrm{~g}$ ). (a) 0.65 bar (b) 0.8 bar.

\subsubsection{Comparison of PAC adsorption methods}

In the previous experiments, PAC was directed added to the feed tank and recirculated during the MD operation. It was confirmed by visual observation that some PAC was deposited on the membrane. Accordingly, it appears that SDS was continuously adsorbed onto PAC in the feed solution as well as on the membrane surface. In Fig. S2 in the supplementary material, a set of $\mathrm{MD}$ experiment was carried out with a different PAC adsorption method. Here, the feed solution was mixed with PAC for $60 \mathrm{~min}$ and filtered using a $0.45 \mathrm{Om}$ microfilter. As a result, no PAC remained during the $\mathrm{MD}$ experiment. Although the initial SDS concentration was $3.0 \mathrm{mg} / \mathrm{L}$, the SDS concentration in the feed solution after the PAC adsorption was $0.3 \mathrm{mg} / \mathrm{L}$. However, the flux increased from the beginning and the permeate conductivity started to increase after $400 \mathrm{~min}$. Unlike the case with the PAC addition without prefiltration (Fig. 4), the effect of PAC adsorption on wetting miti- gation is not significant. In fact, the results were similar to the those without PAC addition (Fig. 2(b)).

The flux and permeate conductivity of the $\mathrm{MD}$ experiments with different PAC adsorption methods were compared in Fig. S3 in the supplementary material. The results are presented as a function of VCF. When PAC was not prefiltered, the flux and conductivity remained almost constant up to the VCF of 2.4. According to the isotherm model previously obtained from the batch tests, the equilibrium concentration of SDS at VCF $=2.4$ was calculated to $0.53 \mathrm{mg} / \mathrm{L}$, which is higher than the initial concentration of SDS in the case of MD with PAC prefiltration $(0.3 \mathrm{mg} / \mathrm{L})$. This implies that there is an additional mechanism of wetting control in the case of $\mathrm{MD}$ without PAC prefiltration or continuous PAC adsorption during $\mathrm{MD}$ operation.

To further investigate the mechanisms of the wetting control, the SEM images of the MD membranes were compared. Fig. S4(a) and S4(b) in the supplementary material show the intact MD membrane and the membrane after the MD operation with PAC prefiltration. No clear difference was found from these two images although the initial wetting was found in Fig. S4(b). This is because the wetting by SDS resulting from the reduction of surface tension cannot be observed using SEM. In Fig. S4(c), the surface of the membrane was covered by PAC deposits. Accordingly, a substantial fraction of the membrane surface is not directly exposed to the feed solution and the PAC deposits seem to cover it to protect from SDS in the feed solution. Since the size of PAC is sufficiently large $(1 \sim 20 \mathrm{~m})$, it does not seem to provide additional resistance to mass transfer. On the other hand, it may act as a protective "coating" against the wetting by SDS.

The proposed mechanism of the PAC effect on the wetting is illustrated in Fig. S5 in the supplementary material. When there was no PAC during MD operation, SDS in the feed solution causes wetting. If SDS concentration is very low, wetting may not occur. However, based on the result in Fig. S2, wetting occurred at even the SDS concentration of $0.3 \mathrm{mg} / \mathrm{L}$, When PAC exists during the $\mathrm{MD}$ operation, the deposition of PAC led to the formation of the PAC layer on the membrane surface (Fig. S5(b)). Accordingly, the PAC concentration at the membrane surface is much higher than that in the feed solution, resulting in very low SDS concentration near the membrane surface. In fact, the adsorbed amount of SDS was $4.5 \mathrm{mg} / \mathrm{g}$ when the initial concentration of SDS was $3 \mathrm{mg} / \mathrm{L}$. This corresponds to 1.4 times higher adsorption compared with the results of the batch adsorption experiments, which can be explained by the PAC layer on the MD membrane surface.

\section{Conclusion}

In this study, a laboratory-scale V-AGMD was used to treat synthetic wastewater containing $\mathrm{NaCl}$ of $50,000 \mathrm{mg} / \mathrm{L}$ and SDS. The PAC adsorption was suggested and applied to mitigate membrane wetting by SDS. Based on the results, the following conclusions were withdrawn:

(1) When SDS exists in the high-salinity feed solution, wetting began within $200 \mathrm{~min}$, leading to rapid increases in the flux and permeate conductivity. Without SDS, wetting occurred due to salt precipitation after 5,000 $\mathrm{min}$, which is 
more than 25 times longer than that with SDS.

(2) The adsorption isotherm of SDS by the PAC used in this study could be described by the Freundlich isotherm with $K_{F}$ of $18.30 \mathrm{mg} / \mathrm{g}$ and $1 / \mathrm{n}$ of 0.7833 .

(3) The addition of the PAC into the feed tank resulted in the dramatic retardation of wetting by SDS. The increase in flux and conductivity were observed after 5,700 min, suggesting that the wetting occurred not by SDS but by salt precipitation.

(4) The effect of PAC on the wetting mitigation was also found at higher vacuum pressures, indicating that a higher degree of vacuum may be used for V-AGMD. Nevertheless, an increase in vacuum reduced the time of wetting occurrence.

(5) When PAC adsorption was implemented prior to $\mathrm{MD}$ operation, wetting still occurred within $200 \mathrm{~min}$ at the reduced SDS concentration $(0.3 \mathrm{mg} / \mathrm{L})$. This is attributed that PAC deposits provide additional protection against wetting by SDS. This suggests that PAC adsorption should be continuously done during the $\mathrm{MD}$ operation.

\section{Acknowledgment}

This work was supported by Korea Environment Industry \& Technology Institute(KEITI) through "A Industrial Facilities \& Infrastructure Research Program”, funded by Korea Ministry of Environment(MOE)(146671).

\section{Author Contributions}

Y.K. (Master Student) conducted all the experiments and wrote the manuscript. S.L. (Professor) revised the manuscript. Y.C. (Associate Professor) revised the manuscript. J.C. (Ph.D. student) conducted the experiments.

\section{References}

1. Chan W-F, Marand E, Martin SM. Novel zwitterion functionalized carbon nanotube nanocomposite membranes for improved RO performance and surface anti-biofouling resistance. $J$. Membr. Sci. 2016;509:125-137.

2. Donato L, Garofalo A, Drioli E, et al. Improved performance of vacuum membrane distillation in desalination with zeolite membranes. Sep. Purif. Technol. 2020;237:116376.

3. Goh PS, Ismail AF. is interplay between nanomaterial and membrane technology the way forward for desalination?. J. Chem. Technol. Biotechnol. 2015;90:971-980.

4. Brunetti A, Macedonio F, Barbieri G, Drioli E. Membrane engineering for environmental protection and sustainable industrial growth: Options for water and gas treatment. Environ. Eng. Res. 2015;20:307-328.

5. Mezher T, Fath H, Abbas Z, Khaled A. Techno-economic assessment and environmental impacts of desalination technologies. Desalination 2011;266:263-273.
6. Choi Y, Lee Y, Shin K, Park Y, Lee S. Analysis of long-term performance of full-scale reverse osmosis desalination plant using artificial neural network and tree model. Environ. Eng. Res. 2020;25:763-770.

7. Park Y, Lee S. Analysis of thermal energy efficiency for hollow fiber membranes in direct contact membrane distillation. Environ. Eng. Res. 2019;24:347-353.

8. Leaper S, Abdel-Karim A, Gad-Allah TA, Gorgojo P. Air-gap membrane distillation as a one-step process for textile wastewater treatment. Chem. Eng. J. 2019;360:1330-1340.

9. Winter D, Koschikowski J, Ripperger S. Desalination using membrane distillation: Flux enhancement by feed water deaeration on spiral-wound modules. J. Membr. Sci. 2012;423:215-224.

10. Qtaishat MR. Design of novel direct contact membrane distillation membranes. Desalination. 2006;192:105-111.

11. Damtie MM, Volpin F, Yao M, et al. Ammonia recovery from human urine as liquid fertilizers in hollow fiber membrane contactor: Effects of permeate chemistry. Environ. Eng. Res. 2021;26:190523-190520.

12. Alsaadi AS, Francis L, Maab H, Amy GL, Ghaffour N. Evaluation of air gap membrane distillation process running under sub-atmospheric conditions: Experimental and simulation studies. J. Membr. Sci. 2015;489:73-80.

13. Garcia-Payo M, Izquierdo-Gil MA, Fernández-Pineda C. Air gap membrane distillation of aqueous alcohol solutions. J. Membr. Sci. 2000;169:61-80.

14. Kullab A. Desalination using membrane distillation: experimental and numerical study. in, KTH Royal Institute of Technology; 2011.

15. Francis L, Ghaffour N, Alsaadi AS, Nunes SP, Amy GL. Performance evaluation of the DCMD desalination process under bench scale and large scale module operating conditions. J. Membr. Sci. 2014;455:103-112.

16. Mericq J-P, Laborie S, Cabassud C. Vacuum membrane distillation of seawater reverse osmosis brines. Water Res. 2010;44:5260-5273.

17. Abu-Zeid MAE-R, Zhang L, Jin W-Y, Feng T, Wu Y, Chen H-L. Improving the performance of the air gap membrane distillation process by using a supplementary vacuum pump. Desalination 2016;384:31-42.

18. Liu Z, Gao Q, Lu X, Ma Z, Zhang H, Wu C. Experimental study of the optimal vacuum pressure in vacuum assisted air gap membrane distillation process. Desalination 2017;414: 63-72.

19. Choudhury MR, Anwar N, Jassby D, Rahaman MS. Fouling and wetting in the membrane distillation driven wastewater reclamation process-A review. Adv. Colloid. Interface. Sci. 2019.

20. Li X, Zhang Y, Cao J et al. Enhanced fouling and wetting resistance of composite Hyflon $\mathrm{AD} /$ poly (vinylidene fluoride) membrane in vacuum membrane distillation. Sep. Purif. Technol. 2019;211:135-140.

21. Han L, Tan YZ, Netke T, Fane AG, Chew JW. Understanding oily wastewater treatment via membrane distillation. J. Membr. Sci. 2017;539:284-294.

22. Gryta M, Karakulski K. The application of membrane distillation for the concentration of oil-water emulsions. Desalination 1999;121:23-29. 
23. Basar CA, Karagunduz A, Cakici A, Keskinler B. Removal of surfactants by powdered activated carbon and microfiltration. Water Res. 2004;38:2117-2124.

24. Siyal AA, Shamsuddin MR, Low A, Rabat NE. A review on recent developments in the adsorption of surfactants from wastewater. J. Environ. Manage. 2020;254:109797.

25. Ince M, Senturk E, Onkal EG, Keskinler B. Further treatment of landfill leachate by nanofiltration and microfiltration-PAC hybrid process. Desalination 2010;255:52-60.

26. Amaral P, Partlan E, Li M, et al. Superfine powdered activated carbon (S-PAC) coatings on microfiltration membranes: Effects of milling time on contaminant removal and flux. Water Res. 2016;100:429-438.

27. Liu J, Tian J, Wang Z, Zhao D, Jia F, Dong B. Mechanism analysis of powdered activated carbon controlling microfiltration membrane fouling in surface water treatment. Colloid Surf.
A-Physicochem. Eng. Asp. 2017;517:45-51.

28. XU L, Wang J, Zhang X, Hou D, Yu Y. Development of a novel integrated membrane system incorporated with an activated coke adsorption unit for advanced coal gasification wastewater treatment. Colloid Surf. A-Physicochem. Eng. Asp. 2015;484: 99-107.

29. Woo YC, Tijing LD, Park MJ, et al. Electrospun dual-layer nonwoven membrane for desalination by air gap membrane distillation. Desalination 2017;403:187-198.

30. Velioğlu S, Han L, Chew JW. Understanding membrane pore-wetting in the membrane distillation of oil emulsions via molecular dynamics simulations. J. Membr. Sci. 2018;551:76-84.

31. Zhang X, Xu J, Lv Z, et al. Preparation and utilization of cigarette filters based activated carbon for removal CIP and SDS from aqueous solutions. Chem. Phys. Lett. 2020;747:137343. 